\title{
Studies Utilizing Current Estimated CSF Pressure Equations Should Not Be Conducted and Published [Letter]
}

\author{
David Fleischman (1D ${ }^{\prime}$ \\ Hanspeter E Killer ${ }^{2}$ \\ 'Department of Ophthalmology, \\ University of North Carolina at Chapel \\ Hill, Chapel Hill, NC, USA; ${ }^{2}$ Department \\ of Ophthalmology, Kantonsspital Aarau, \\ Aarau, Switzerland
}

Correspondence: David Fleischman Department of Ophthalmology, University of North Carolina at Chapel Hill, 5 I 26 Bioinformatics Bldg \#7040, Chapel Hill, NC, 27599-7040, USA

Tel $+1919259-9336$

Fax + I 919 966-1908

Email david8fleischman@gmail.com

\section{Dear editor}

We took interest in the recent article by Qian Wang and colleagues, "Prevalence of Retinal Vein Occlusions and Estimated Cerebrospinal Fluid Pressure: The Kailuan Eye Study."1 We agree with the authors that CSF pressure, in particular the perioptic subarachnoid space pressure, is likely important in the development of many cases of retinal vein occlusions. However, we were troubled by the methodology employed by the study team. While we appreciate the mention of our study ${ }^{2}$ that had found that formulae used to predict CSFP derived from clinical data were unable to accurately estimate CSF pressures, we were surprised that this formula was nonetheless used in the current study.

Even more troubling is that the reference given for the justification of the formula, ${ }^{3}$ "eCSFP $[\mathrm{mm} \mathrm{Hg}]=0.44 *$ BMI $[\mathrm{kg} / \mathrm{m} 2]+0.16$ * DBP [mm Hg] -0.18 * Age [years]," does not in fact explain its derivation. The Xie study from Critical Care used patientspecific anatomic measurements derived from MRI data in order to estimate CSFP, an important factor that has been excluded from the current study's equation.

CSF pressure is not static. It varies over time as a function of the production and resorption rate of CSF and body posture. A formula that is derived top down from preexisting data (such as BMI and DBP) is far from representing the complexity of CSF dynamics, including CSF pressure. Neither is CSF pressure and composition homogeneous throughout all CSF-containing spaces. Further, even if it could reflect the appropriate CSF pressure in the lumbar spine region, it is purely speculative to assume that this measurement could be extrapolated to the pressure within the subarachnoid space of the optic nerve. Several studies in patients with papilledema as well as normal tension glaucoma demonstrated "comparted" optic nerve sheaths, ${ }^{4}$ a finding that cautions even the assumption that the pressure measured at the lumber site reflects the pressure in the perioptic space. Thus, to assume that all CSF spaces connect via a linear continuum can be quite misleading.

In conclusion, we are strongly supportive of research that will further the understanding of the cerebrospinal fluid's role in ophthalmic disease. However, bad data are worse than no data.

We would have expected that the limitations of such a study should have been clearly explained to the reader who may not be familiar with this complex topic, and we discourage the use of unvalidated formulae for CSF and ophthalmic research. 


\section{Disclosure}

Dr David Fleischman reports on personal fees from Optopol, outside the submitted work. The authors report no other conflicts of interest in this communication.

\section{References}

1. Wang Q, Yang J, Jonas JB, et al. Prevalence of retinal vein occlusions and estimated cerebrospinal fluid pressure: the Kailuan Eye Study. Eye Brain. 2021;13:147-156. PMID: 34045911; PMCID: PMC8149277. doi:10.2147/EB.S290107
2. Fleischman D, Bicket AK, Stinnett SS, et al. Analysis of cerebrospinal fluid pressure estimation using formulae derived from clinical data. Invest Ophthalmol Vis Sci. 2016;57(13):5625-5630. PMID: 277 60263. doi:10.1167/iovs.16-20119

3. Xie X, Zhang X, Fu J, et al.; Beijing iCOP Study Group. Noninvasive intracranial pressure estimation by orbital subarachnoid space measurement: the Beijing Intracranial and Intraocular Pressure (iCOP) Study. Crit Care. 2013;17(4):R162. PMID: 23883736; PMCID: PMC 4056099. doi: $10.1186 / \mathrm{cc} 12841$

4. Killer HE, Subramanian PS. Compartmentalized cerebrospinal fluid. Int Ophthalmol Clin. 2014;54(1):95-102. PMID: 24296374. doi:10. 1097/IIO.0000000000000010

Dove Medical Press encourages responsible, free and frank academic debate. The content of the Eye and Brain 'letters to the editor' section does not necessarily represent the views of Dove Medical Press, its officers, agents, employees, related entities or the Eye and Brain editors. While all reasonable steps have been taken to confirm the content of each letter, Dove Medical Press accepts no liability in respect of the content of any letter, nor is it responsible for the content and accuracy of any letter to the editor

Eye and Brain

\section{Publish your work in this journal}

Eye and Brain is an international, peer-reviewed, open access journal focusing on clinical and experimental research in the field of neuroophthalmology. All aspects of patient care are addressed within the journal as well as basic research. Papers covering original research, basic science, clinical and epidemiological studies, reviews and

Submit your manuscript here: https://www.dovepress.com/eye-and-brain-journal evaluations, guidelines, expert opinion and commentary, case reports and extended reports are welcome. The manuscript management system is completely online and includes a very quick and fair peerreview system, which is all easy to use. Visit http://www.dovepress. com/testimonials.php to read real quotes from published authors. 